\title{
Can one do good medical ethics without principles?
}

\author{
Ruth Macklin
}

\section{Correspondence to}

Professor Ruth Macklin, Department of Epidemiology \& Population Health, Albert Einstein College of Medicine, Bronx, NY 10461, USA; ruth.macklin@einstein.yu.edu

Received 20 August 2014 Revised 5 September 2014 Accepted 2 October 2014
CrossMark

To cite: Macklin R. J Med Ethics 2015;41:75-78.

\section{ABSTRACT}

The criteria for determining what it is to do good medical ethics are the quality of ethical analysis and ethical justifications for decisions and actions. Justifications for decisions and actions rely on ethical principles, be they the 'famous four' or subsidiary ethical principles relevant to specific contexts. Examples from clinical ethics, research ethics and public health ethics reveal that even when not stated explicitly, principles are involved in ethical justifications. Principles may come into conflict, however, and the resolution of an ethical dilemma requires providing good reasons for preferring one principle over another.

Here is a simple answer to the question, 'what is it to do good medical ethics?' It depends. It depends on what criteria are used to determine that what is being done is good. The appropriate criteria for determining what is good work in this field relate to the two main activities of applied ethics: the quality of ethical analysis and ethical justifications for decisions and actions. We know what count as bad justifications. To mention only a few: 'The decision appeared to me in a dream'; 'I flipped a coin to decide'; 'I followed what my (mother, father, teacher, mentor) always did'; 'I sought an answer from God'; 'I followed my (instinct, intuition).'

Some people might demur at rejecting the last alleged justification and possibly also the next-to-last. But since I consider doing medical ethics to be a rational activity, none of the items on the list count as a justification for decisions or actions-or at least not without additional rational justification.

It is easier to say what it is to do bad medical ethics than what it is to do good medical ethics. Two candidates for bad medical ethics are flawed or inadequate methodology in reaching ethical judgments and making ethically wrong decisions.

The bad justifications mentioned above are brief examples of flawed methodology; more detailed examples are discussed below. Making ethically wrong decisions is much more problematic, however, since medical ethics almost always involves controversy or uncertainty about what is the right thing to do. Uncertainty in deciding and acting can stem from empirical considerations, such as insufficient evidence or inability to predict the future. Current examples in medical practice include disagreements about the use of certain diagnostic tests, such as prostate-specific antigen (PSA) screening for prostate cancer ${ }^{1}$ and the value of bilateral mastectomy in women diagnosed with cancer in one breast. ${ }^{2}$ The controversies that are most fraught, however, are those that arise from a conflict of ethical principles.

A frequent source of controversy in clinical ethics is conflicts between two of the 'famous four' principles: ${ }^{3}$ beneficence and respect for autonomy. Such cases often come before a committee on which I serve at my institution, which advises on cases brought by physicians working in the institution's infertility practice. It is sometimes questioned whether the use of ethical principles is of any value for doctors in medical practice. The following examples show how ethical analysis can go wrong (or simply not exist) in the absence of principles.

\section{HOW ETHICS COMMITTEES CAN DO GOOD MEDICAL ETHICS}

Committee members have disagreed about the acceptability of providing infertility treatments to postmenopausal women: Are the risks to a 60 -year-old too great to warrant subjecting her to hormonal treatments, undergoing a pregnancy and childbirth? Or, if the risks have been explained and she understands them, does respect for her autonomy justify going ahead with treatment? Except for those who would claim that autonomy should always trump beneficence (and I do not know of anyone in this category), cases like this do pose genuine ethical dilemmas. But in this example there is also empirical uncertainty, since little or no evidence of pregnancy in 60-year-olds exists. These same two principles came into conflict in another case before the committee. A woman with multiple medical ailments sought assistance for her infertility. Here again, respect for her autonomy was at issue, but the risks of pregnancy and childbirth, together with the very low probability that she would achieve a pregnancy given her other medical conditions, led to the conclusion that beneficence should trump respect for autonomy. The committee reasoned that the risks to her, along with the expected futility of the treatment (lack of benefit), justified denying her request.

How can one analyse such cases and 'do good medical ethics' without using principles? Here is one possible alternative. When the first 58-year-old couple (newly married) came to the infertility clinic seeking treatment, one of the physicians on the committee said, 'I can't try to help this woman become pregnant; she looks like a grandmother!' This came to be known as the 'yuck factor' in medical ethics. Can one use the yuck factor and do good medical ethics?

Apparently, some who purport to do medical ethics think so. In 1997, the American essayist Leon Kass wrote an article entitled 'The Wisdom of Repugnance." The article was about human 
cloning, and Kass's reaction to the very idea of cloning a human being was revulsion. The same moral sentiments that make (most) human beings feel repugnance at the idea of cannibalism operate in the case of cloning humans, Kass wrote, and there is a certain 'wisdom' in these deep-seated emotional responses. So imagine how this would play out in a discussion in medical ethics intended to lead to a decision. One person argues that if the 58-year-old woman understands the risks to her (and maybe also the potential fetus) of pregnancy and childbirth, the doctors should respect her autonomy. Another committee member replies 'yuck!' That is not doing good medical ethics. 'Yuck' is a conversation stopper, not an argument.

Recognising that 'Yuck!' is not an argument, opponents of treating the 58-year-old woman switch tactics (a typical move when one's position is not succeeding). Now they invoke a principle: the best interest of the child (which in this case can be considered a version of beneficence). 'What about the child?' they ask. 'Is it in the best interest of a child to be born of parents who look like the child's grandparents?'

'Is it in the best interest of a child who may be orphaned while still in grade school?'

The philosopher on the committee pipes up: "What child? The one waiting in the wings who might be born instead to a 28-year-old couple? Or is this a choice between which state of affairs is better: never to exist? or to be born the child of 59-year-old parents?' This excursion into metaphysics meets with stunned silence from other committee members. They have never read Derek Parfit. ${ }^{5}$ Committee members who invoked the best interest of the child did introduce a principle into the discussion, and to that extent they were doing good medical ethics. However, their response to the non-identity problem would be viewed by many as flawed reasoning. We are trying to do good medical ethics, not metaphysics.

A third case that came before the same committee is also instructive. It involved a request by the couple seeking infertility treatment to choose the sex of their child.

Prenatal sex determination is a controversial issue in the field of assisted reproduction. Since the treatment in this case involved in vitro fertilisation (IVF), the possibility existed of using prenatal genetic testing to determine the sex of the embryos created by IVF and choosing only embryos of the desired sex to transfer to the woman's uterus. The committee appropriately examined the couple's reasons for wanting to choose the sex of their child. After determining that the couple had sound (or at least, acceptable) reasons and did not display prejudice against members of the sex they were deciding against, the committee voted in favour of complying with the couple's request. Most committee members concurred that respect for autonomy was the appropriate justification. One committee member voted against the decision. When asked for his reason, he simply said: 'I'm opposed to sex selection of embryos.' He did not say he was opposed to the destruction of otherwise healthy embryos. He did not say he was concerned about an imbalance in the sex ratio (unlike in China and India, there is no disproportionate number of males to females in the sex ratio in the USA and surveys have shown that parents have equal preferences for having male or female children). He simply asserted his opinion. Assertions that are not justified by reasons-especially principled reasons-are not good medical ethics.

\section{HOW TO DO GOOD MEDICAL ETHICS IN MULTICULTURAL SETTINGS}

A never-ending debate persists over whether ethical principles should be considered universal, thereby applying to situations anywhere in the world, or whether local or regional cultural norms and values must be respected in the context of medical treatment or research. Defenders of the latter position argue that respect for culture is a principle that justifies cultural ethical relativism. A typical move is to claim that the widely cited four principles of medical ethics are 'Western' principles that are inapplicable in, say, Asia or Africa. A useful way of thinking about this is the distinction Beauchamp and Childress make between 'universal morality' and 'community-specific morality,' where the latter 'includes the moral norms that spring from particular cultural, religious, and institutional sources' (p. 3). ${ }^{3}$

Among the most typical circumstances in which cultural practices constitute violations of ethical principles are those involving informed consent and disclosure of information to patients. Requiring a husband's permission to treat his wife violates her autonomy, yet this is common practice in quite a few traditional cultures. The proposed solution to the dilemma a European or North American physician may face is to approach the patient (assuming that is feasible) and ask whether she is willing to have her husband decide for her. She is almost certain to answer 'yes,' which may not be a genuine exercise of autonomy because her acceptance of the common practice is culturally determined and not a product of her deliberation and independent choice. In the clinical context, however, this is not a difficult problem. If the patient needs treatment and the only way treatment can be administered is for the physician to obtain permission from her husband, it is an acceptable course of action. It is a compromise, since circumstances preclude the doctor being able to respect the woman's autonomy. Failure to treat the woman would result in harm; treating her is more likely to benefit than to harm her; and although her autonomy is not respected, the physician employs another relevant principle-in this case, beneficence.

In the field of research ethics, in contrast to medical practice, there is by now a settled, worldwide acceptance of the need for individual informed consent, in compliance with respect for autonomy, wherever the research is being carried out.

The principle is enshrined in international ethics guidance such as the Declaration of Helsinki ${ }^{6}$ and the Council for International Organizations of Medical Sciences International Ethical Guidelines for Biomedical Research Involving Human Subjects. ${ }^{7}$ If potential female subjects must have the permission of their spouse to enter a study, researchers could consider those women ineligible for failing to meet one of the required eligibility criteria for research. If, on the other hand, the practice of spousal authorisation is a general cultural requirement in the community or country, a dilemma can arise. Either forgo doing research in that setting or do the research in compliance with local custom. A committee of which I was a member at WHO confronted this dilemma after a human rights lawyer and I protested when we saw the signature line for spousal authorisation on the consent forms for research.

Because this was a frequent problem the committee faced, the need arose for a policy addressing the matter. The human rights lawyer and I-along with other committee members-were vehement in insisting that research should not be undertaken in such communities. However, the program officer in the Department of Reproductive Health and Research, where the committee was appointed, provided a counterargument. $\mathrm{He}$ pointed out that in the country in question, as well as others with similar norms, women would not have access to the successful products of research unless the research was carried out in that country. Many governments would not allow products to be marketed and purchased by the Ministry of Health unless the 
product is tested on the population in the country. The program officer claimed that if women in the population were denied the future benefits of reproductive health research, they would be worse off. Without identifying it by name, the program officer was invoking the principle of beneficence. Forgo the research, and an entire population of women would be denied potential benefits; conduct the research, and forgo adherence to respect for (individual) autonomy. The eventual policy drafted by the committee spelled this out, saying this should be a rare situation, but made clear that in no case should a husband be permitted to put his wife into research without her informed consent.

Here again, even if her consent is informed, it may not be truly voluntary because of her adherence to the cultural norm rather than being an authentic choice of her own. Doing good medical ethics sometimes requires compromises. But the compromise was not to abandon the use of principles. Rather, it was to use one respected ethical principle (beneficence) where the preferred principle in this situation (respect for autonomy) could not readily be adhered to.

At times, a respected principle can yield conflicting decisions in a true dilemma.

Consider the case of a European physician approached by African immigrant parents who request that the physician perform ritual genital cutting on their daughter. (Assume in this example that there is no law in the European country that prohibits physicians from performing female genital cutting.) The parents tell the physician that they want the procedure done hygienically by a physician; however, if a European physician refuses to perform the cutting, they will send their daughter back to Somalia where native practitioners will perform the ritual without anaesthesia and with possibly unclean instruments. The physician invokes non-maleficence. She would be doing harm if she cuts the genitals of the adolescent girl. But she would be allowing greater harm to occur if she refuses and the parents send their daughter back to Somalia. She would be denying parental autonomy by refusing the parents' request. And what if the girl, understanding all this, requests the physician to do the cutting? Although the methodology using principles provides no clear answer to this dilemma, neither does any other methodology in medical ethics.

\section{THE PRINCIPLE OF JUSTICE}

The medical ethics literature contains a large and increasing number of articles on setting priorities when health resources are limited. Even when justice is not mentioned explicitly (and it often is), the question in many settings revolves around a just allocation of medical resources. Among others, here are a few contexts in which a fair allocation of resources must be made: distributing vaccines in an outbreak of cholera; allocating ventilators to people who have contracted influenza in an epidemic; allocating organs for transplantation; and determining who should receive HIV therapeutic medicines when there are not enough for all who need them. Justice is not the only principle that enters into discussion nor is there only one version of that principle. Competing principles are invoked when disagreement arises. In a disease outbreak, the utilitarian principle, 'save the most lives,' can compete with a principle of justice, especially when a version of the latter principle is interpreted to include serving the 'least advantaged' members of the population-the version known as the prioritarian principle. 'Save the most lives' is an interpretation of the principle of beneficence since it calls for maximising beneficial outcomes. This is an example of a conflict of principles in which policy makers have to decide whether justice should trump beneficence. Another version of a justice principle is egalitarianism. An egalitarian principle used in the context of priority setting competes with the prioritarian version and 'maximising lives saved,' as it requires giving everyone an equal chance through a mechanism such as a lottery. In the context of organ transplantation, the most common allocation scheme is first come first served, though a second principle is used when some individuals on the waiting list are moved up in accordance with the principle of urgent need (they will deteriorate further and die if not moved up ahead of others on the waiting list).

Subsidiary principles may have to be invoked when a universal principle lacks sufficient granularity for an allocation scheme. The principle of urgent need, mentioned above, is an example of a subsidiary principle. Another used in situations of scarce resources is fair innings: the view that younger people should get the scarce resource before older people, since the former have not yet had a fair share of the normal life expectancy. Much debate exists in practical contexts, such as decision making in public health contexts, over which conception of the principle of distributive justice is most suitable. In some cases, where no reasonable criteria exist for choosing among alternatives, tossing a coin may well be the fairest method. But there could be no discussion at all without a reliance on principles.

\section{CONCLUSIONS}

Having defended the use of principles (more specifically, the famous four), I end by acknowledging that an ethical analysis need not invoke these or other principles explicitly. They may be lurking in the background, however. Other useful ethical concepts are often central to an ethical analysis. In research ethics, for example, much discussion centres on the concept of clinical equipoise: whether it is always necessary for proposed research to have it, and circumstances when it may be acceptable to conduct research in the absence of equipoise. Although none of the four principles may be mentioned explicitly, it is evident that discussions involving equipoise can be based on an interpretation of what beneficence or justice requires.

If a control group in a randomised, controlled trial receives a placebo rather than a proven treatment, is it fair to allow that group not to receive what is available outside the trial? Some argue it can be fair because the experimental treatment in the other arm of the trial may not be efficacious or may even be harmful. Others contend that it is unfair to provide research participants with an intervention that is less than what they would receive if treated by their physician. Arguably, the question of placebos can also be analysed using the principle of beneficence. If there exists an obligation to minimise risks to subjects and maximise potential benefits (to the subjects or others) in clinical trials, then assigning placebo to one arm in a trial when an efficacious intervention exists outside the trial fails to maximise benefits and minimise risks to those subjects. Yet, some argue that as long as potential subjects are fully informed and consent to participate, respect for autonomy can justify their inclusion in a placebo-controlled trial.

It is hard to understand how one can do good medical ethics without relying-explicitly or implicitly—on ethical principles to justify decisions and actions. One can tell stories, as in narrative ethics. But what happens in stories can be a poor guide to ethical action. One can appeal to the virtues of a physician or other health professional. But as is well known, a person can act out of a virtuous motive that results in a bad outcome, or a bad motive can yield a good outcome. As John Stuart Mill famously wrote, '...the motive has nothing to do with the morality of the 
action, though much with the worth of the agent." ${ }^{8}$ As important as virtues are for assessing the character of physicians and other moral agents, they are of little value in justifying decisions or actions.

It is true, of course, that principles by themselves do not yield unique answers to ethical quandaries. It is also true that two individuals using ethical principles can reach incompatible conclusions. But this does not show that principles are useless.

Ethical arguments can be supported by better or worse reasons, so it is necessary to evaluate an argument as a whole. Beauchamp and Childress are the first to admit the limitations of principles in resolving ethical controversies: '...we acknowledge that our moral framework does not resolve a priori conflicts among principles and rules' (p. 388). ${ }^{3}$ But since the criteria for determining what is good medical ethics are the quality of ethical analysis and the ethical justifications for decisions and actions, the famous four principles provide the best approach.
Competing interests None.

Provenance and peer review Commissioned; internally peer reviewed.

\section{REFERENCES}

1 Schröder FH, Hugosson J, Roobol MJ, et al. Screening and prostate cancer mortality: results of the European Randomised Study of Screening for Prostate Cancer PSA (ERSPC) at 13 years of follow-up. Lancet. Published Online First: 6 Aug 2014. doi:10.1016/S0140-6736(14)60525-0

2 Orenstein P. The wrong approach to breast cancer. The New York Times, $26 \mathrm{Jul}$ 2014. http://www.nytimes.com/2014/07/27/opinion/sunday/the-wrong-approach-tobreast-cancer.html (accessed 20 Aug 2014).

3 Beauchamp TL, Childress JF. Principles of biomedical ethics. 5th edn. New York: Oxford University Press, 2001.

4 Kass LR. The wisdom of repugnance. New Repub 1997;216(22):17-26.

5 Parfit D. Reasons and persons. Oxford: Oxford University Press, 1984.

6 World Medical Association. Declaration of Helsinki. 2013. http://www.wma.net/en/ 30publications/10policies/b3/ (accessed 20 Aug 2014).

7 Council for International Organizations of Medical Sciences (CIOMS). Geneva, Switzerland: CIOMS, 2002.

8 Mill JS. What utilitarianism is. In: Utilitarianism. 1863. http://www.utilitarianism.com/ mill2.htm (accessed 20 Aug 2014). 